\title{
Tidal Mixing Signatures in the Hong Kong Coastal Waters from Satellite-Derived Sea Surface Temperature
}

\author{
R. Dwi Susanto ${ }^{1,2,3, * \mathbb{D}}$, Jiayi Pan ${ }^{3,4,5} \mathbb{D}$ and Adam T. Devlin ${ }^{3,5} \mathbb{C}$ \\ 1 Department of Atmospheric and Oceanic Science, University of Maryland, College Park, MD 20742, USA \\ 2 Faculty of Earth Sciences and Technology, Bandung Institute of Technology, Bandung 40132, Indonesia \\ 3 Institute of Space and Earth Information Science, The Chinese University of Hong Kong, Hong Kong, China; \\ panj@cuhk.edu.hk (J.P.); phlux1@gmail.com (A.T.D.) \\ 4 College of Marine Science, Nanjing University of Information Science and Technology, Nanjing 210044, \\ Jiangsu, China \\ 5 Shenzhen Research Institute, The Chinese University of Hong Kong, Shenzhen 518172, Guangdong, China \\ * Correspondence: dwisusa@umd.edu; Tel.: +1-845-666-3003
}

Received: 8 November 2018; Accepted: 15 December 2018; Published: 20 December 2018

\begin{abstract}
Tidal mixing in the coastal waters of Hong Kong was investigated using a combination of in situ observations and high-resolution satellite-derived sea surface temperature (SST) data. An indicator of tide-induced mixing is a fortnightly (spring-neap cycle) signature in SST due to nonlinear interactions between the two principal diurnal and the two principal semi-diurnal tides. Both semi-diurnal and diurnal tides have strong tidal amplitudes and currents near Hong Kong. As a result, both the near-fortnightly (Mf) and fortnightly (MSf) tides are enhanced due to nonlinear tidal signal interactions. In addition, these fortnightly tidal signals are modulated by seasonal variability, with the maximum seasonal modulation of fortnightly tides occurring during the monsoon transition periods in May and October. The largest fortnightly signals are found in the southwestern part of the Pearl River estuary. Tidal constituent properties vary by space and depth, and high-resolution SST plays a pivotal role in resolving the spatial characteristics of tidal mixing.
\end{abstract}

Keywords: ocean tidal mixing; the South China Sea; sea surface temperature; Hong Kong coastal water; fortnightly tides

\section{Introduction}

The Hong Kong coastal waters are part of the South China Sea (SCS), which is the largest marginal sea in Southeast Asia (Figure 1). The Hong Kong coastal waters exhibit strong semi-diurnal and diurnal tides [1] and are likely to have strong tidal mixing due to nonlinear interactions between multiple bands of the tidal spectrum. Strong mixing is expected along the coast of China, based on numerical model results [2]. Various tidal phenomena in the SCS have drawn attention because of their complicated characteristics and have been the focus of many diverse oceanographic studies. These tidal studies can be summarized into three themes: (a) analysis of harmonic constants based on limited tide gauge station data or mooring data in the SCS (e.g., [3-6] and references therein), (b) analysis of results based on 2D or 3D numerical models and data assimilation [2,7-12], and (c) analysis of altimeter data in the SCS (e.g., $[13,14])$ to obtain the tidal constituents. However, no previous studies have been reported on the extraction of nonlinear tidal interactions and tidal mixing signatures from a combination of satellite sea surface temperature (SST) data and in situ measurements in the Hong Kong area or the SCS. It is desirable to determine the spatial characteristics of tidal mixing in the Hong Kong coastal waters due to pressing concerns about the coastal environment and pollution, especially 
mass exchanges between the SCS waters and the Pearl River plumes. In this study, we aim to illustrate spatial tidal mixing characteristics in the Hong Kong coastal waters due to nonlinear interactions between tidal signals.

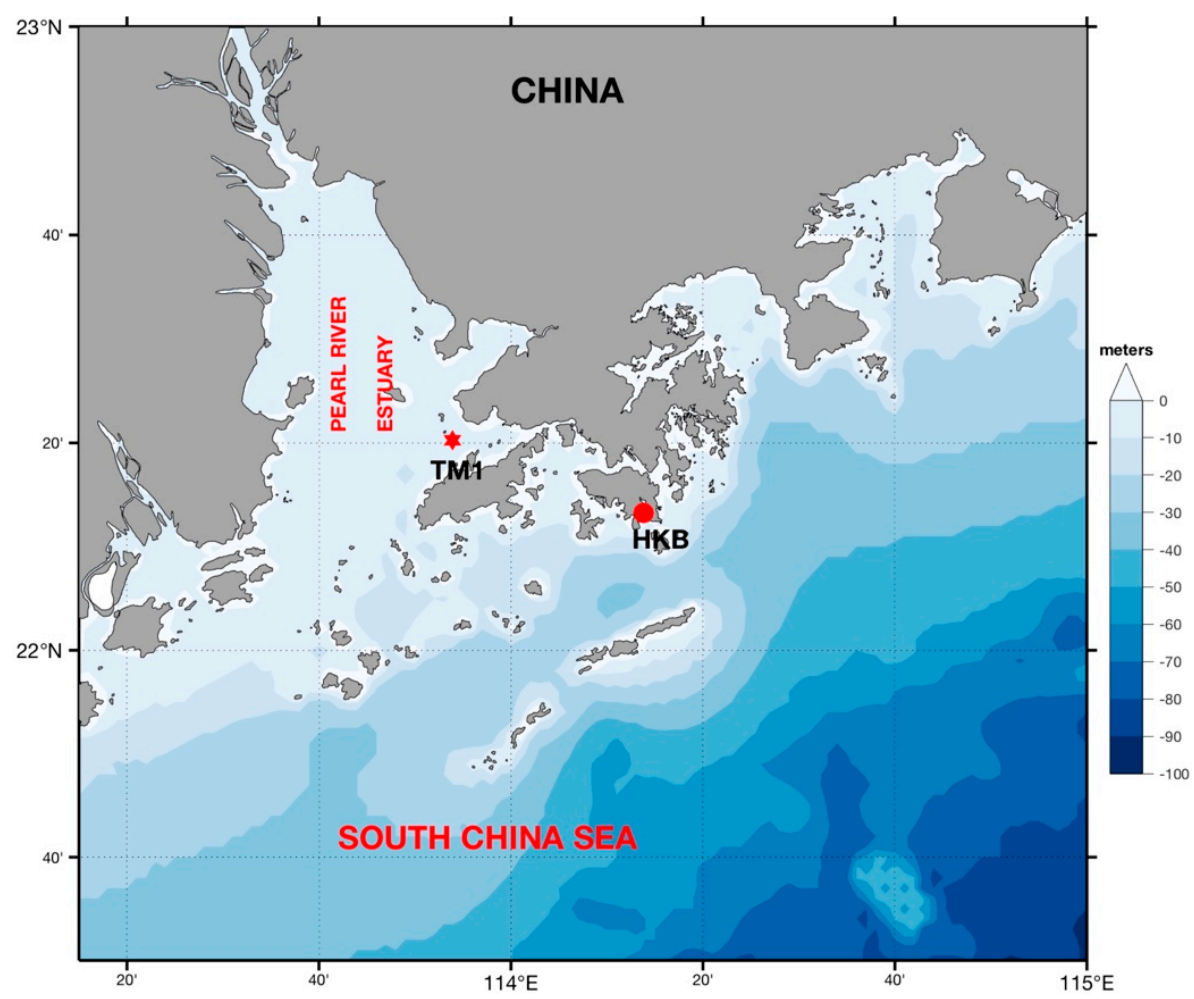

Figure 1. The Hong Kong coastal waters, in the northern part of the South China Sea. The red star and circle denote the locations of the RDI $1200 \mathrm{kHz}$ bottom-mounted acoustic Doppler current profilers (ADCP) deployed off the coast of Sha Chau Marine Park (TM1) at $113.899^{\circ} \mathrm{E}$ and $22.338^{\circ} \mathrm{N}$ from 6 June 2010 to 1 June 2011 (red star), and off the coast of Hong Kong Island near Stanley (HKB) at $114.216^{\circ} \mathrm{E}$ and $22.221^{\circ} \mathrm{N}$ from 1 January 2012 to 31 December 2012 (red circle).

\section{Methods}

\subsection{Tidal Mixing and Ocean Currents}

The salient approach involved in the analysis of SST for tidal mixing signatures is to search for a (near-fortnightly) spring-neap cycle in the data using harmonic analysis. It is hypothesized that tidal mixing can lower SST as cooler subsurface water is mixed into the surface layer and that the cooling would be proportional to the intensity of the mixing. Turbulent mixing can be parameterized by assuming that the square of the tidal current is proportional to the effect of turbulent mixing on temperature $[15,16]$, and therefore, the change in ocean temperature induced by tidal mixing depends upon the square of the tidal current velocities. Both flood and ebb tidal speeds would, therefore, act to cool SST. The stronger tidal currents that occur during spring tides can enhance the mixing, allowing colder subsurface water to lower SST [15,17] and reduce the stratification [18]. Twice each month, tidal amplitudes and currents reach a maximum during spring tides when $\mathrm{M}_{2}$ and $\mathrm{S}_{2}$ or $\mathrm{K}_{1}$ and $\mathrm{O}_{1}$ work together. $\mathrm{M}_{2}$ is the principal semi-diurnal lunar tide with a period of $\mathrm{T}_{\mathrm{M} 2}=0.5175$ day, and $\mathrm{S}_{2}$ is the principal semi-diurnal solar tide with a period of $\mathrm{T}_{\mathrm{S} 2}=0.5000$ days. $\mathrm{K}_{1}$ is a diurnal lunar tide with a period of $\mathrm{T}_{\mathrm{K} 1}=0.99727$ day, and $\mathrm{O}_{1}$ is a diurnal solar tide with a period of $\mathrm{T}_{\mathrm{O} 1}=1.07581$ days [16]. If the amplitude of the SST spring-neap cycle is significantly above the background noise, it is a likely sign that some tidal mechanism, including tidal mixing, is involved [19]. 
A linear superposition of the diurnal lunar tide $\left(\mathrm{K}_{1}\right)$ and diurnal solar tide $\left(\mathrm{O}_{1}\right)$ has a modulation envelope with a period of 13.66 days (the near-fortnightly, Mf).

$$
A_{1} \cos \left(\omega_{K 1}\right) t+A_{2} \cos \left(\omega_{O 1}\right) t
$$

where $A_{1}$ and $A_{2}$ are the amplitudes of $\mathrm{K}_{1}$ and $\mathrm{O}_{1}$, respectively, and $\omega_{\mathrm{K} 1}$ and $\omega_{\mathrm{O} 1}$ are the angular frequency of $\mathrm{K}_{1}$ and $\mathrm{O}_{1}$, respectively. Similarly, a linear combination of the principal semi-diurnal constituents, $\mathrm{M}_{2}$ and $\mathrm{S}_{2}$, should have a modulation envelope of the fortnightly signal (MSf) with a period of 14.77 days. However, the amplitude of a simple linear tidal superposition due to lunar and solar gravitational interactions is very small and too weak to be involved in the physics of mixing [19].

Taking the square of this combination will produce nonlinear terms with new periodicities (e.g., [16]).

$$
0.5\left(A_{1}^{2}+A_{2}^{2}\right)+0.5\left(A_{1}^{2} \cos 2 \omega_{K 1} t+A_{2}^{2} \cos 2 \omega_{O 1} t\right)+A_{1} A_{2} \cos \left(\omega_{K 1}+\omega_{O 1}\right) t+A_{1} A_{2} \cos \left(\omega_{K 1}-\omega_{O 1}\right) t
$$

with oscillations at higher frequencies of $2 \omega_{\mathrm{K} 1}, 2 \omega_{\mathrm{O} 1}$, and $\left(\omega_{\mathrm{K} 1}+\omega_{\mathrm{O} 1}\right)$, with a period of approximately 0.5175 day, as well as at a lower frequency $\left|\omega_{\mathrm{K} 1}-\omega_{\mathrm{O} 1}\right|$, with a period of 13.66 days (the same period of the near-fortnightly tidal constituent, Mf). Similarly, nonlinear interactions between the principal semi-diurnal constituents, $\mathrm{M}_{2}$ and $\mathrm{S}_{2}$, will generate a fortnightly signal, with a period of 14.77 days.

In this manner, nonlinear interactions between tidal constituents (depending on the strength of the component) can generate a near-fortnightly signal with a period of 13.66 days, and a fortnightly signal with a period of 14.77 days. These signals have the same periods as the near-fortnightly, Mf ( $\mathrm{T}=13.66$ days), and fortnightly, MSf (14.77 days), tidal constituents generated by the equilibrium tide. Hereafter, SST signatures at the near-fortnightly frequency will be denoted as Mf, and the signatures at the fortnightly frequency will be denoted as MSf.

Recently, Ray and Susanto [19] used ultra-high-resolution SST to show evidence of strong tidal mixing in the Indonesian seas, which can be detected as a spring-neap tidal cycle in satellite-observed SST. They concluded that the largest fortnightly signals (MSf) observed from the satellite SST are found to be in relatively small straits, channels, and sills. Nugroho et al. [2] studied tidal mixing in the Southeast Asia seas using a numerical model that includes tides. In the Indonesian seas, their results are similar to Ray and Susanto [19]. Additionally, they showed a strong tidal mixing (MSf signal) along the southern coast of China and in the Andaman Sea. In this study, we determine the spatial tidal mixing characteristics in the Hong Kong coastal waters using a combination of multi-scale ultra-high-resolution satellite SST and in situ measurements of pressure and ocean currents to examine the existence of the spring-neap signals of Mf and MSf.

Depending on the strength of semi-diurnal and diurnal tides in the region, fortnightly signals can be observed at the Mf or MSf frequency. While tides in the deep basin of SCS are weak, semi-diurnal $\left(\mathrm{M}_{2}\right)$ and diurnal $\left(\mathrm{O}_{1}\right)$ tides in the slope and shelf of northern SCS are strong, and tidal velocities may reach up to $0.1 \mathrm{~ms}^{-1}$ in the Taiwan Strait [8]. The slope and shelf regions are expected to have strong fortnightly tidal mixing due to nonlinear interactions between semi-diurnal and diurnal tides (especially over sills or other topographic features (i.e., [6]), and near the Pearl River plume. Both satellite SST and in situ measurements of ocean currents show a spring-neap signal at fortnightly frequencies that will be discussed in the following section.

\subsection{Satellite-Based SST and In Situ Velocity Data}

Daily multi-scale ultrahigh resolution SST (MUR-SST) data covering the period from 1 June 2002 to 31 December 2015 were provided by NASA's Jet Propulsion Laboratory (JPL) [20-22]. SST products from multiple satellites (based on infrared and microwave sensors) were merged using an objective analysis and wavelet decomposition method [22]. The MUR-SST data are available with a regular latitude-longitude grid spatial resolution of $0.01^{\circ}$ (approximately $1 \mathrm{~km}$ ). 
In situ data, velocity and pressure measurements were obtained from a bottom-mounted acoustic doppler current profiler (ADCP) off the coast of Sha Chau Marine Park (TM1) and off the coast of Stanley, Hong Kong Island (HKB) at a water depth of approximately $10 \mathrm{~m}$. The RDI $1200 \mathrm{kHz}$ ADCP was set to record velocity (at $0.75 \mathrm{~m}$ vertical resolution) and pressure data at two-hour time intervals from 6 June 2010 to 1 June 2011 and from 1 January 2012 to 31 December 2012 for Sha Chau Marine Park and Stanley, respectively. The ADCP is equipped with a pressure sensor, which records pressure variability near the bottom and represents the variability of the total water column from the ADCP to the surface.

\subsection{Tidal Analysis}

The Hong Kong coastal waters show significant geographical variability of tidal characteristics. Harmonic tidal analysis of pressure and velocity time series was carried out using the "Utide" Matlab package [23]. The "Utide" package integrates several existing tidal analysis methods including the "t_tide" [24] and "r_t_tide" packages [25], which have become a widely accepted standard utility in the physical oceanographic community. One of the advantages of "Utide" is that it allows a multi-year time series of observations with temporally irregular sampling.

The harmonic tidal analysis process was applied to a velocity time series at every bin-depth of the ADCP (11 bins for the HKB and 12 bins for the TM1 mooring locations), which produces 59 tidal constituents from low to high frequencies (Sa to M8) for every bin-depth of the time series. A tidal constituent is significant if the amplitude is larger than its confidence interval [23]. The results of the harmonic analysis of tidal heights and velocities at TM1 and HKB mooring locations show compound and shallow water constituents $\left(\mathrm{M}_{4}, \mathrm{M}_{6}, \mathrm{MN}_{4}, 2 \mathrm{MN}_{6}, \mathrm{MS}_{4}\right.$, and $\left.2 \mathrm{MS}_{6}\right)$ that are above the confidence intervals. These terms are the result of $\mathrm{M}_{2}$ interacting with the $\mathrm{N}_{2}$ and $\mathrm{S}_{2}$ constituents. The shallow water tides make the velocity profile more asymmetric, which may lead to larger velocity and shear-induced mixing that contributes to the fortnightly signals [26]. These results indicate that $\mathrm{N}_{2}$ is important and shallow water hydrodynamics can affect the tidal characteristics in the Hong Kong area. The effect of the nonlinear terms in the shallow water equations of motion on a tidal constituent causes a modulation or distortion of that constituent, which can be represented by the combination of that constituent with one or more new constituents $[27,28]$.

\section{Results and Discussion}

Figure 2 shows: (a) ADCP time series of vertical shear velocity $\left(\mathrm{m} \mathrm{s}^{-1}\right)$ deployed off the coast of Sha Chau Marine Park (TM1) within the vicinity of the Pearl River estuary (Figure 1, red star), (b) time series of pressure (dbar), and (c-f) the power spectrum density of mean tidal current, shear, surface tidal current squared, and pressure, respectively. The spectra are calculated using a multi-taper spectral density estimate and with $95 \%$ confidence interval [29,30]. Figure 3 is similar to Figure 2 but for the coast of Stanley, Hong Kong Island (Figure 1, red circle). Both the HKB (Stanley) and TM1 (Marine Park) stations show strong/sharp and coherent $\mathrm{K}_{1}, \mathrm{O}_{1}$, and $\mathrm{M}_{2}$ and $\mathrm{S}_{2}$ peaks. The peaks are sharper south of Hong Kong Island, but less coherence is observed west of Hong Kong Island. From the mean velocity, shear, velocity squared, and pressure power spectra plots, it can be seen that both diurnal components and both semi-diurnal components have strong peaks. However, the pressure spectrum does not exhibit strong peaks of the Mf and MSf frequencies at TM1 (Sha Chau Marine Park) or HKB (Stanley coast) mooring locations. At TM1 (Figure 2c,e) the velocity and velocity squared spectra of Mf and MSf are significant. The lower $95 \%$ confidence level (dotted lines) of Mf and MSf frequencies are above the upper $95 \%$ confidence level outside the vicinity of these fortnightly frequencies. At HKB (Figure 3c), the velocity spectrum is within the margin of the lower $95 \%$ confidence level. The velocity squared spectrum of MSf (Figure 3e) shows a wider peak at the MSf frequency. 

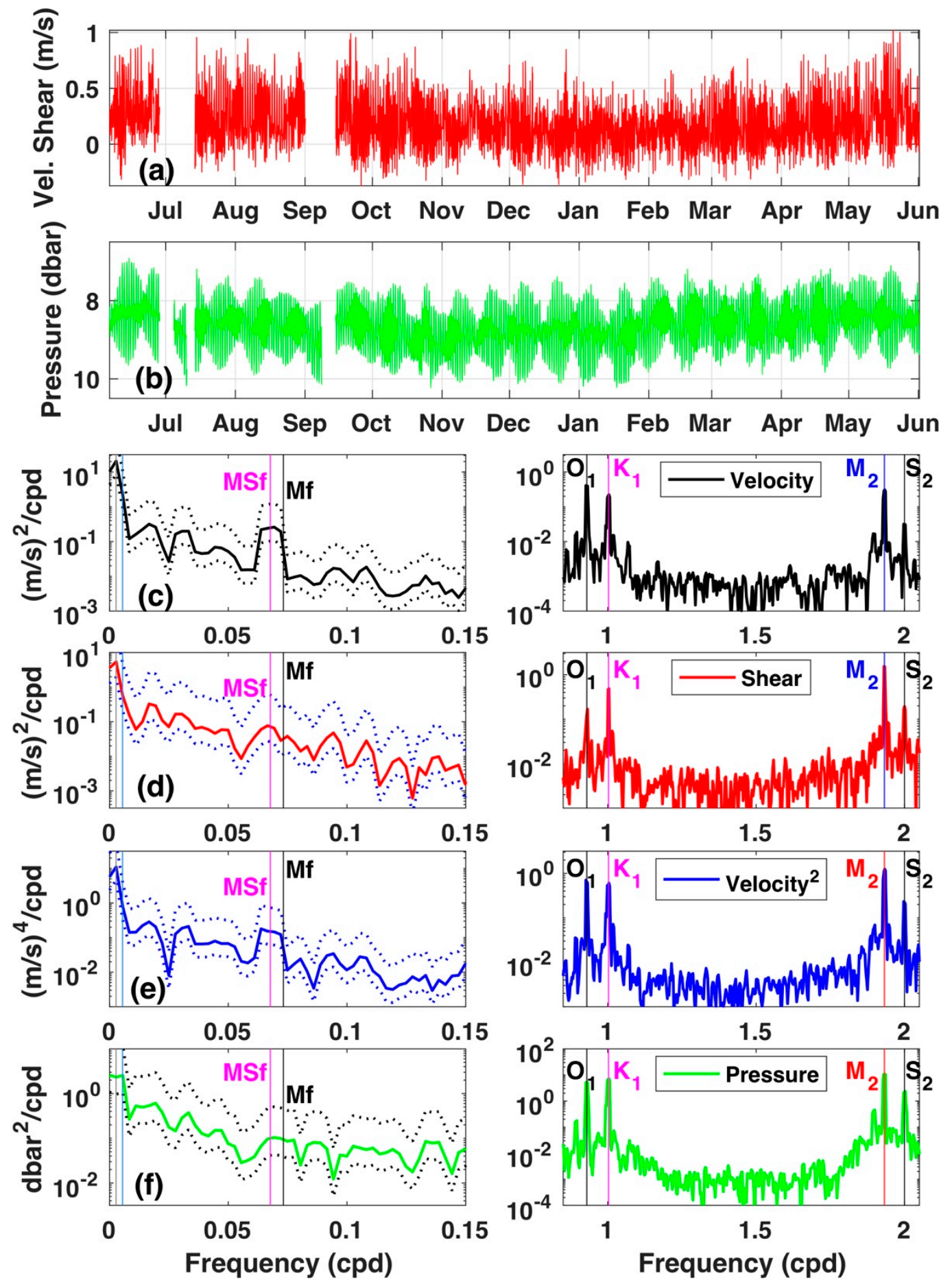

Figure 2. (a) Vertical shear (near surface velocity minus near bottom velocity, $\mathrm{m} \mathrm{s}^{-1}$ ) time series observed using bottom-mounted acoustic Doppler current profiler (ADCP) deployed off the coast of Sha Chau Marine Park (TM1) from 6 June 2010 to 1 June 2011. (b) The pressure time series (dbar). (c-f) The power spectral density of mean velocity, shear, surface velocity squared, and pressure, respectively. The temporal mean has been removed from the pressure time series before applying the power spectral analysis. Labeled vertical dashed lines mark frequencies of the semi-diurnal $\left(\mathrm{M}_{2}\right.$ and $\left.\mathrm{S}_{2}\right)$ and diurnal $\left(\mathrm{O}_{1}\right.$ and $\left.\mathrm{K}_{1}\right)$ tides as well as the long-period tides (MSf and Mf). The vertical lines (cyan and gray) in the far left of the spectrum represent semi-annual and annual frequencies, respectively. The dotted lines in panels (c-f) denote the upper and lower bounds of $95 \%$ confidence interval. 

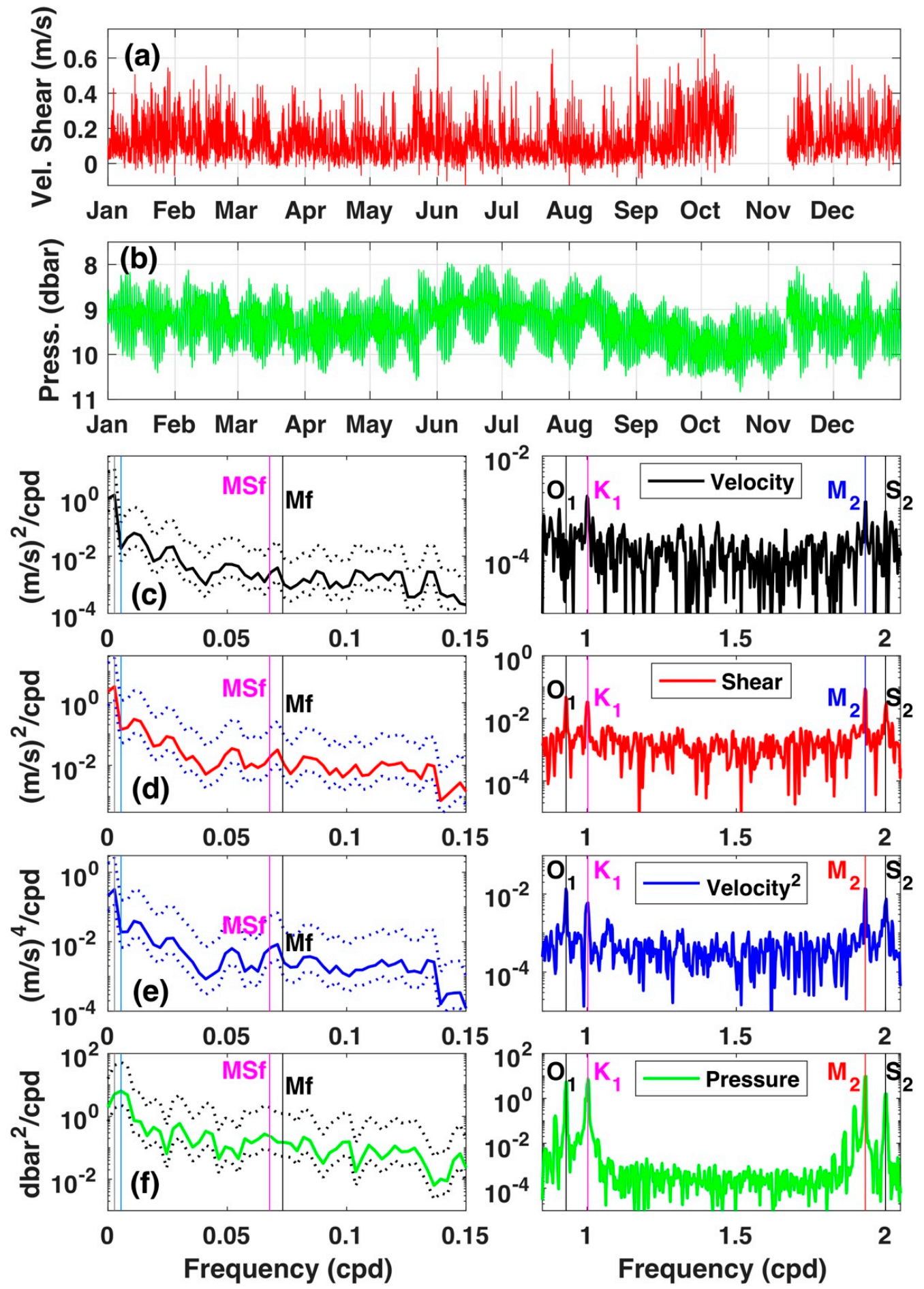

Figure 3. Similar to Figure 2 for the Stanley, Hong Kong coast (HKB) mooring location. (a) Velocity shear (near surface minus near bottom velocity, $\mathrm{m} \mathrm{s}^{-1}$ ) time series from January 1, 2012 to December 31, 2012. (b) The pressure time series (dbar). (c-f) The power spectral density of mean velocity, shear, surface velocity squared, and pressure, respectively.

It is now clear that semi-diurnal and diurnal tides are strong around Hong Kong, and if tidal mixing does occur, it is expected to be observed as a near-fortnightly signal (Mf) associated with nonlinear interactions between $\mathrm{O}_{1}$ and $\mathrm{K}_{1}$, as well as a fortnightly signal (MSf) associated with nonlinear interactions between $\mathrm{M}_{2}$ and $\mathrm{S}_{2}$ in the SST data. This is indeed what was observed at both locations studied (TM1 and HKB), i.e., the spectrum of velocity squared showed wider peaks 
of Mf and MSf, indicating that mixing does occur at these two stations (TM1 is stronger). The power spectral density of velocity squared was sharper and stronger than that of pressure, showing that the mixing-related nonlinear interactions between tidal constituents contribute more to the observed fortnightly signals than the equilibrium tide. The SST results (discussed below) support these findings.

Following Ray and Susanto [19], tidal mixing signatures were extracted from 13.5 years of daily MUR-SST data (from June 1, 2002 through December 31, 2015). Figure 4 shows the results of the extracted Mf and MSf amplitudes, which are only plotted if the signal is more than 1.75 the standard error (see Ray and Susanto, 2016 for the method). The near-fortnightly signal (Mf) is more dominant than the fortnightly (MSf) signal.
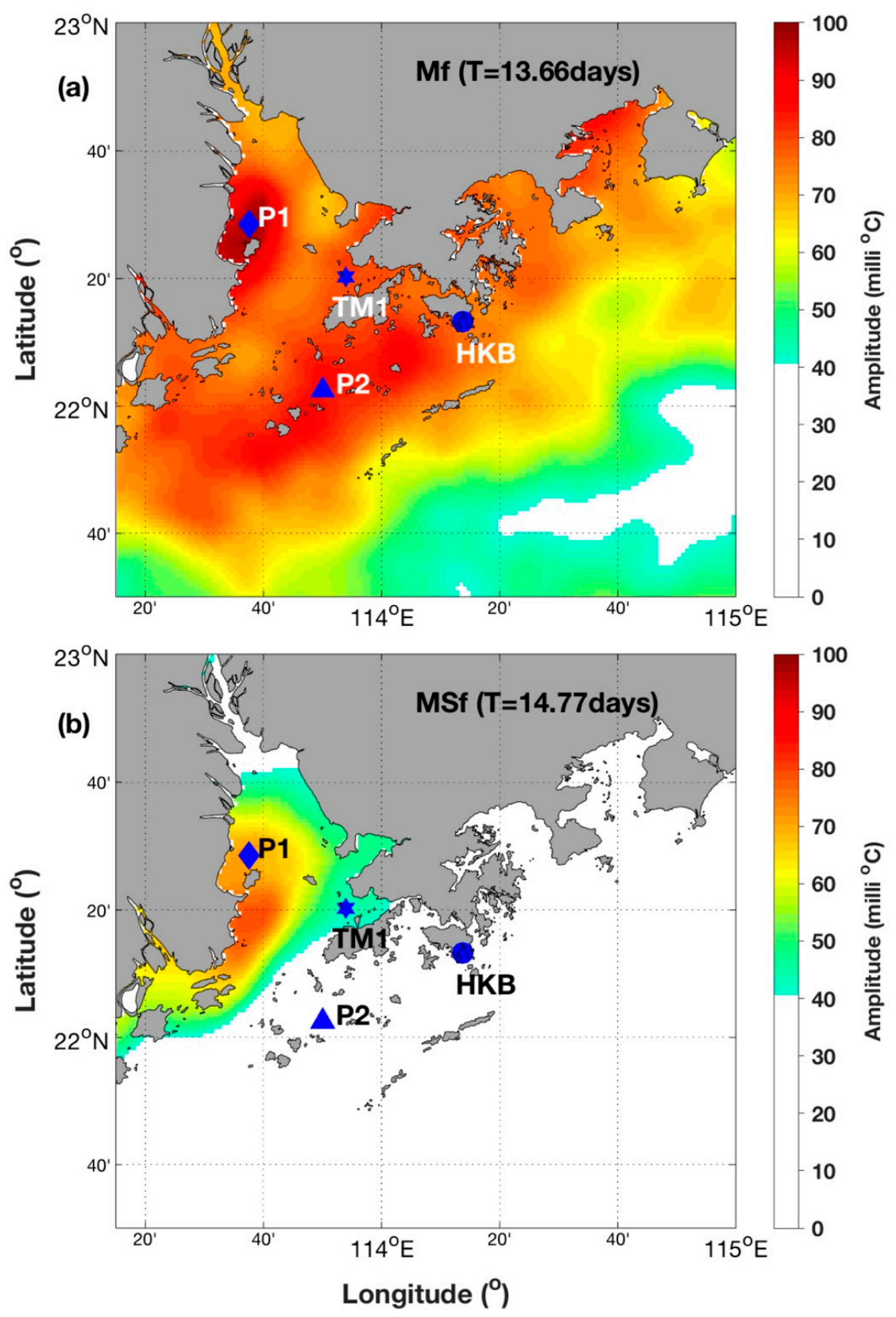

Figure 4. Estimates of amplitude (in milli-Celsius) of fortnightly (spring-neap cycle) of Mf (a) and MSf (b) tidal components in sea surface temperature, extracted from 13.5 years of daily MUR-SST data. The blue star and circle are the locations of the bottom mounted acoustic Doppler current profilers (ADCPs) at Sha Chau Marine Park station (TM1) and Stanley, Hong Kong (HKB), respectively. 
Four locations, P1, P2, TM1 (Marine Park) and HKB, were selected to further reveal the fortnightly signals in SST (Figure 4). P1 is located inside the Pearl River estuary, with a high-amplitude SST signature in both Mf and MSf signals. TM1 is located in the Pearl River estuary mouth (west of Hong Kong Island), while HKB and P2 are located outside the estuary; all three stations have a relatively moderate amplitude of Mf and a weaker MSf signal. The Mf signal was observed across nearly all of the study area of the Hong Kong coastal waters and its vicinity within the South China Sea. A large Mf signal was observed near the small islands around P2, and the largest signal was observed at P1, indicating that diurnal tidal components are stronger than the semi-diurnal components. The strongest Mf signals in Figure 4a have amplitudes in the order of 100 milli-Celsius $\left(0.1^{\circ} \mathrm{C}\right)$ located on the southern side of the Pearl River. At the location of the ADCPs at TM1 and HKB, the Mf amplitude was 80 milli-Celsius.

Figure 5 shows the power spectral density of the MUR-SST data at four selected locations. At P1, there are clear Mf and MSf peaks in the SST power spectral density. At TM1 and HKB, MSf is weaker, but a strong Mf signal is seen. All four locations displayed moderate fortnightly energy in the SST power spectral density, indicating that the tidal mixing signatures in SST result from the nonlinear interactions between $\mathrm{O}_{1}$ and $\mathrm{K}_{1}$ and between $\mathrm{M}_{2}$ and $\mathrm{S}_{2}$, which were observed in the in situ velocity and bottom pressure data. At TM1 and HKB, the Mf signature was slightly larger than that of MSf because $\mathrm{S}_{2}$ energy was less significant than that of $\mathrm{M}_{2}, \mathrm{O}_{1}$ and $\mathrm{K}_{1}$ (Figures 2 and 3) in Hong Kong and the SCS. Meanwhile, at P1 the MSf is slightly larger than that of Mf. The right panel is an expanded view of the power spectral density from the range of 0.06 to $0.08 \mathrm{cpd}$, which shows an additional peak at $0.075 \mathrm{cpd}$ (i.e., at $\mathrm{Mf}+$ one cycle per year), which indicates a seasonal modulation of the $\mathrm{Mf}$ signal. Figure 6 shows seasonal variations of fortnightly oscillations of SST at P1, P2, TM1, and HKB. More intense modulation of fortnightly signals was observed at P1 and TM1 with the maxima occurring during the monsoon transitions in May and October. The spectra also show monthly (Mm) and semi-annual (Ssa) and annual (Sa) signals. There was no clear peak in the monthly signal. Strong peaks of semi-annual and annual signals indicate that SST variability in the Hong Kong coastal waters are strongly affected by seasonal signals associated with monsoons that modulate the spring-neap signals.

Additionally, we used the regional inverse model (TPX08_atlas_30_ver1) of Egbert and Erofeeva [31], which is defined on a $1 / 30^{\circ}$ grid. Figure 7 shows spectra of the velocity synthetic time series based on the TPX08 at P1, P2, TM1, and HKB. Observations at P1 showed stronger semi-diurnal and diurnal signals as well as fortnightly signals. These results confirm our findings (based on the SST data) that tidal mixing at P1 is important. Note that the inverse model gives barotropic velocity only; in shallow water, the baroclinic part may be substantial and mostly responsible for the mixing [32]. The mixing depends strongly on baroclinic ocean currents, stratification, and the Richardson number $[33,34]$. The SST signature from vertical tidal mixing depends on the strength of the current and local vertical temperature gradient. Therefore, there is a possibility that an area with only moderate mixing but a strong $\mathrm{dT} / \mathrm{dz}$ might show a strong mixing signature in SST. Conversely, some areas may have a strong vertical mixing but weak $\mathrm{dT} / \mathrm{dz}$. However, the variability of $\mathrm{dT} / \mathrm{dz}$ at the specific frequencies of fortnightly Mf and MSf are most likely due to tidal mixing. Even though the SST signature and an inverse model may be able to locate or narrow down the potential location of strong tidal mixing, a caveat is given on the need for improved ground-truthing. For example, the question of why the SST signature at P1 is large, while the signal near the small islands around P2 is not so large, has not yet been resolved. 

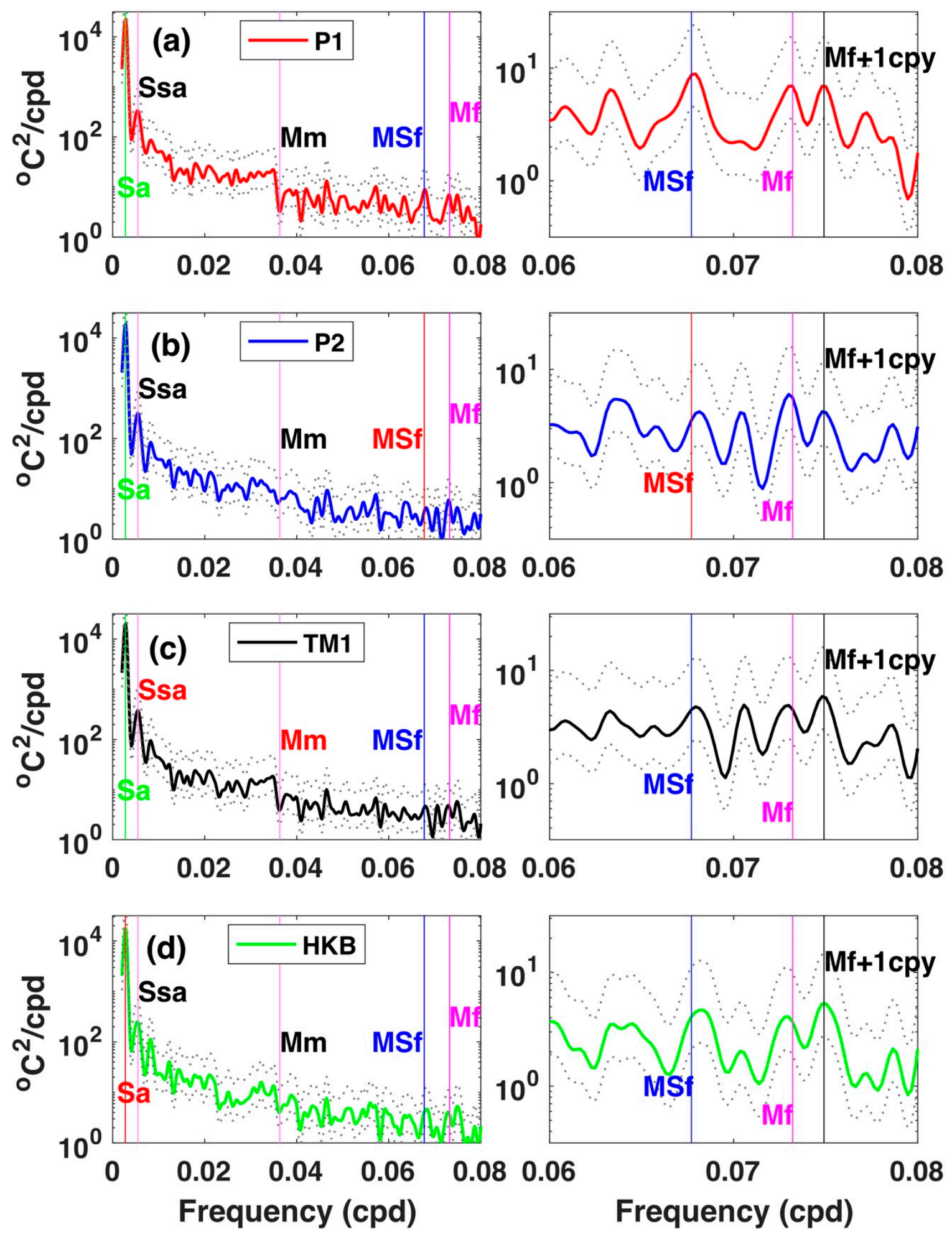

Figure 5. Sea surface temperature (SST) spectra of multi-scale ultrahigh resolution SST (MUR-SST) time series selected at four locations (a) P1, (b) P2, (c) TM1, and (d) HKB) and its zoom near the MSf and Mf frequencies (right panels). Labeled vertical lines mark frequencies of fortnightly (Mf, MSf), monthly $(\mathrm{Mm})$, semiannual (Ssa) and annual (Sa). There is an additional peak at $0.075 \mathrm{cpd}$ which corresponds to Mf plus one cycle per year, which indicates the seasonal modulation of the Mf signal. The dotted lines denote the upper and lower bounds of the $95 \%$ confident interval of the SST spectrum. 


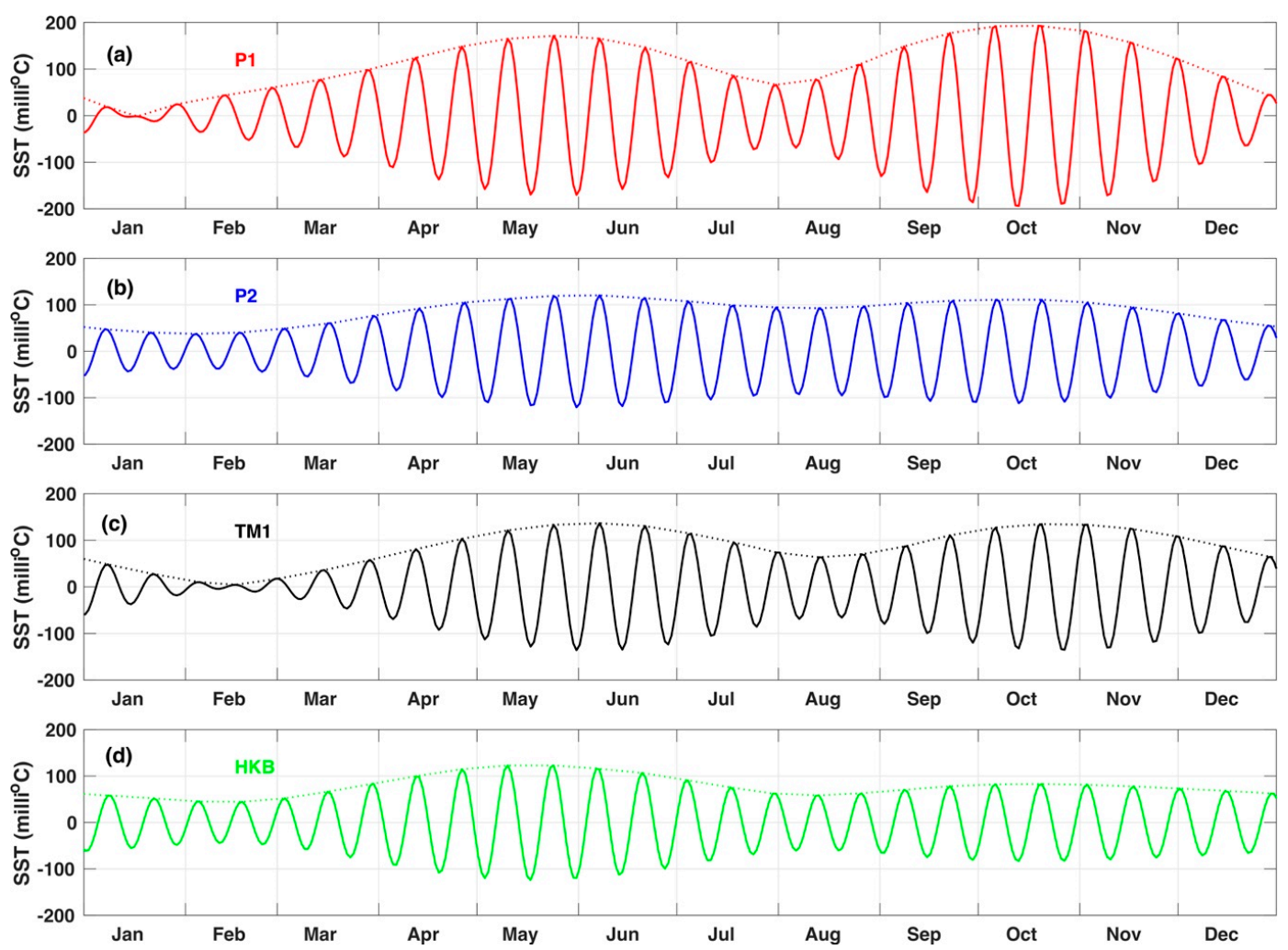

Figure 6. Seasonal variations of the fortnightly oscillation of sea surface temperature (SST) in Hong Kong coastal waters at four selected locations (a) P1, (b) P2, (c) TM1, and (d) HKB, respectively. The dotted lines denote the seasonal modulation/envelope of the fortnightly signals. More intense modulation of fortnightly signals is observed at P1 and TM1 with the maximum occurs during the monsoon transitions in May and October.

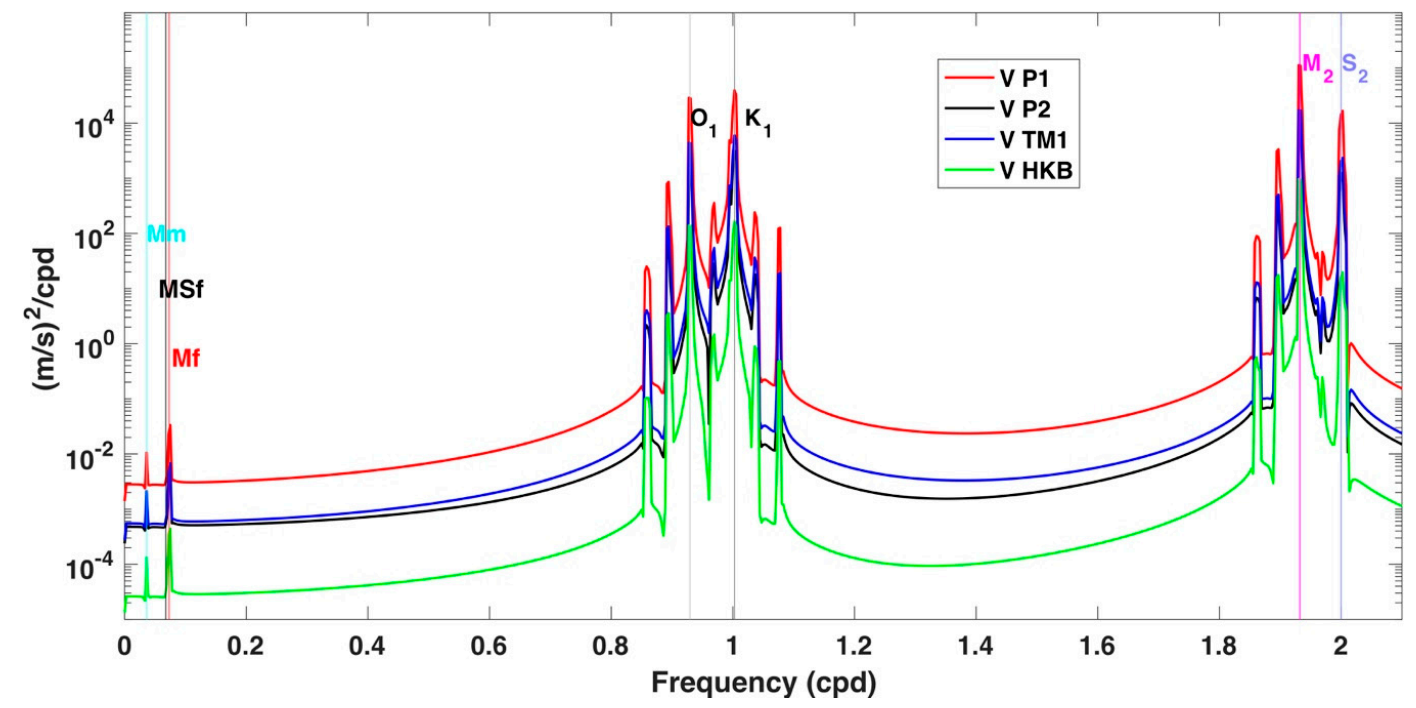

Figure 7. Spectra of velocity-squared based on the velocity prediction/inverse solutions [31] at P1, P2, TM1, and HKB locations.

\section{Conclusions}

Pressure and velocity power spectra in the Hong Kong area reveal that both diurnal tides $\left(\mathrm{O}_{1}\right.$ and $\left.\mathrm{K}_{1}\right)$ and semi-diurnal tides $\left(\mathrm{M}_{2}\right.$ and $\left.\mathrm{S}_{2}\right)$ are strong, though the Pearl River may have an influence on the tidal energy in the region. The Stanley station to the south of Hong Kong Island 
shows a stronger and more coherent $\mathrm{K}_{1}, \mathrm{O}_{1}, \mathrm{M}_{2}$ and $\mathrm{S}_{2}$ spectral peak than the Marine Park station to the west of Hong Kong Island. However, these spectra do not reveal strong peaks at the Mf and MSf frequencies, indicating that the fortnightly tides do not directly lead to mixing. On the other hand, power spectra of satellite-derived SST exhibit strong peaks at both Mf and MSf frequencies, especially inside the Pearl River estuary. This indicates the importance of tidal mixing processes in the region with a near-fortnightly signal (Mf) associated with the nonlinear interaction between $\mathrm{O}_{1}$ and $\mathrm{K}_{1}$ and a fortnightly signal (MSf) associated with nonlinear interaction between $\mathrm{M}_{2}$ and $\mathrm{S}_{2}$. Seasonal modulation of the Mf signal is also observed.

Our results help to clarify how tidal mixing can change the coastal thermal structure in the Hong Kong region. The amplitude of tidal mixing signatures from the SST observations depends on the quality of the SST product; the temporal averaging of the satellite-derived SST data may decrease the Mf and MSf signals in the SST. However, in situ observations are needed for validation. The issue can be solved in the future if we have long-term temperature observations at some fixed locations, i.e., at the moorings site, or P1 and P2 locations, to further validate our findings. More accurate tidal data in the SCS would help numerical modeling efforts in the SCS, and therefore, improve numerical simulations and forecasts of the ocean environment.

Author Contributions: Conceptualization, R.D.S. and J.P.; Methodology, R.D.S.; Software, R.D.S.; Validation, R.D.S., J.P. and A.T.D.; Formal Analysis, R.D.S.; Investigation, R.D.S. and A.T.D.; Resources, R.D.S. and J.P.; Data Curation, R.D.S. and J.P.; Writing-Original Draft Preparation, R.D.S. and J.P.; Writing-Review \& Editing, J.P. and A.T.D.; Visualization, R.D.S.; Supervision, R.D.S. and J.P.; Project Administration, R.D.S. and J.P.; Funding Acquisition, R.D.S. and J.P. All authors contributed to the discussion and manuscript revision.

Funding: This work is supported by the National Natural Science Foundation of China (Projects 41376035), the General Research Fund of Hong Kong Research Grants Council (RGC) under Grants CUHK 14303818, 402912, and 403113, and the Hong Kong Innovation and Technology Fund under Grant ITS/321/13.

Acknowledgments: We would like to thank Richard Ray (NASA) for his fruitful discussions, and the Civil Engineering and Development Department (CEDD), Hong Kong for providing in situ ADCP data. The MURSST data were obtained the NASA Physical Oceanography Distributed Active Archive Center (PODAAC), Pasadena. We appreciate the valuable comments from three anonymous reviewers.

Conflicts of Interest: The authors declare no conflict of interest.

\section{References}

1. Fang, G. Nonlinear effect of tidal friction, II. Acta Oceanologica Sinica 1981, 6 (Suppl. 1), 105-122.

2. Nugroho, D.; Koch-Larrouy, A.; Gaspar, P.; Lyard, F.; Reffray, G.; Tranchant, B. Modelling explicit tides in the Indonesian seas: An important process for surface sea water properties. Mar. Pollut. Bull. 2017, 131, 7-18. [CrossRef] [PubMed]

3. Beardsley, R.C.; Duda, T.F.; Lynch, J.F.; Irish, J.D.; Ramp, S.R.; Chiu, C.-S.; Tang, T.Y.; Yang, Y.-J.; Fang, G. Barotropic tide in the northeast South China Sea. IEEE J. Ocean. Eng. 2004, 29, 1075-1086. [CrossRef]

4. Cai, Y.; Guo, P.; Fang, W.-D. Internal tides in the northern South China Sea from 20-day in-situ mooring observations in 1998. Mar. Pollut. Bull. 2012, 14, 12-23.

5. Wei, Z.X.; Fang, G.H.; Susanto, R.D.; Adi, T.R.; Fan, B.; Setiawan, A.; Li, S.; Wang, Y.G.; Gao, X.M. Tidal elevation, current and energy flux in the area between the South China Sea and Java Sea. Ocean Sci. 2016, 12, 2831-2861. [CrossRef]

6. Alford, M.H.; Peacock, T.; MacKinnon, J.A. The formation and fate of internal waves in the South China Sea. Nature 2015, 521. [CrossRef] [PubMed]

7. Hatayama, T.; Awaji, T.; Akitomo, K. Tidal currents in the Indonesian Seas and their effect on transport and mixing. J. Geophys. Res. 1996, 101, 12353-12373. [CrossRef]

8. Fang, G.; Kwok, Y.-K.; Yu, K.; Zhu, Y. Numerical simulation of principal tidal constituents in the South China Sea, Gulf of Tonkin and Gulf of Thailand. Cont. Shelf Res. 1999, 19, 845-869. [CrossRef]

9. Cai, S.; Huang, Q.; Long, X. Three-dimensional numerical model study of the residual current in the South China, Sea. Oceanol. Acta. 2003, 26, 597-607. [CrossRef]

10. Zu, T.; Gan, J.; Erofeeva, S.Y. Numerical study of the tidal and tidal dynamics in the South China Sea. Deep-Sea Res. Part I 2008, 55, 137-154. [CrossRef] 
11. Xie, J.; Counillo, F.; Zhu, J.; Bertno, L. An eddy resolving tidal-driven model of the South China Sea assimilating along-track SLA data using the EnOI. Ocean Sci. 2011, 7, 609-627. [CrossRef]

12. Choi, B.H.; Min, B.I.; Kim, K.O.; Yuk, J.H. Wavetide-surge coupled simulation for typhoon Maemi. China Ocean Eng. 2013, 27, 141-158. [CrossRef]

13. Mazzega, P.; Bergé, M. Ocean tides in the Asian semi-enclosed seas from TOPEX/ POSEIDON. J. Geophys. Res. 1994, 99, 24867-24881. [CrossRef]

14. Yanagi, T.; Takao, T.; Marimoto, A. Co-tidal and co-range charts in the South China Sea derived from satellite altimetry data. La Mer 1997, 35, 85-93.

15. Ffield, A.; Gordon, A.L. Tidal mixing signatures in the Indonesian seas. J. Phys. Oceanogr. 1996, 26, $1924-1937$. [CrossRef]

16. Pugh, D.; Woodworth, P. Sea Level Science: Understanding Tides, Surges, Tsunamis and Mean Sea-Level Changes; Cambridge University Press: Cambridge, UK, 2014.

17. Souza, A.J.; Pineda, J. Tidal mixing modulation of sea surface temperature and diatom abundance in Southern California. Cont. Shelf Res. 2001, 21, 651-666. [CrossRef]

18. Nunes-Vaz, R.A.; Lennon, G.W.; Samarasinghe, J.R. The negative role of turbulence in estuarine mass transport. Estuar. Coast. Shelf Sci. 1989, 28, 361-377. [CrossRef]

19. Ray, R.D.; Susanto, R.D. Tidal mixing signatures in the Indonesian seas from high-resolution sea surface temperature data. Geophys. Res. Lett. 2016, 43. [CrossRef]

20. JPL MUR MEaSUREs Project, 2010, GHRSST Level-4 MUR Global Foundation Sea Surface Temperature Analysis Version 1, PO DAAC, CA, USA. Available online: http://dx.doi.org/10.5067/GHNMR-4FJ01 (accessed on 19 March 2016).

21. Chin, T.M.; Vazquez, J.; Armstrong, E. Algorithm Theoretical Basis Document: A Multi-Scale, High-Resolution Analysis of Global Sea Surface Temperature, Version 1.3; Jet Propulsion Laboratory: Pasadena, CA, USA, 2013.

22. Chin, T.M.; Vazquez-Cuervo, J.; Armstrong, E. Multi-scale high-resolution analysis of global sea surface temperature. Remote Sens. Environ. 2017, 200, 154-169. [CrossRef]

23. Codiga, D.L. Unified Tidal Analysis and Prediction Using the UTide Matlab Functions; Technical Report 2011-01; Graduate School of Oceanography, University of Rhode Island: Narragansett, RI, USA, 2011.

24. Pawlowicz, R.; Beardsley, B.; Lentz, S. Classical tidal harmonic analysis with errors in matlab using t-tide. Comput. Geosci. 2002, 28, 929-937. [CrossRef]

25. Leffler, K.E.; Jay, D. Enhancing tidal harmonic analysis: Robust (hybrid L1/L2) solutions. Cont. Shelf Res. 2009, 29, 78-88. [CrossRef]

26. Simpson, J.H.; Brown, J.; Matthews, J.; Allen, G. Tidal straining, density currents and stirring control of estuarine stratification. Estuaries 1990, 13, 125-132. [CrossRef]

27. Parker, B.B. Tidal Analysis and Prediction; NOAA special publication, NOS-COPS 3; National Oceanic and Atmospheric Administration (NOAA): Silver Spring, MD, USA, 2007.

28. MacMahan, J.; Kreeke, J.; Reniers, A.; Elgar, S.; Raubenheimer, B.; Thornton, E.; Weltmer, M.; Rynne, P.; Brown, J. Fortnightly tides and subtidal motions in a choked inlet. Estuar. Coast. Shelf Sci. 2014, 150, 325-331. [CrossRef]

29. Percival, D.B.; Walden, A.T. Spectral Analysis for Physical Applications: Multitaper and Conventional Univariate Techniques; Cambridge University Press: Cambridge, UK, 1993.

30. Thomson, D.J. Spectrum estimation and harmonic analysis. Proc. IEEE 1982, 70, 1055-1096. [CrossRef]

31. Egbert, G.D.; Erofeeva, S.Y. Efficient inverse modeling of barotropic ocean tides. J. Atmos. Ocean. Technol. 2002, 19, 183-204. [CrossRef]

32. Geyer, W.R. Tide-induced mixing in the Amazon frontal zone. J. Geophys. Res. 1995, 100, 2341-2353. [CrossRef]

33. Hetzel, Y.; Pattiaratchi, C.; Lowe, R. Intermittent dense water outflows under variable tidal forcing in Shark Bay, Western Australia. Cont. Shelf Res. 2013, 66, 36-48. [CrossRef]

34. Hetzel, Y.; Pattiaratchi, C.; Lowe, R.; Hofmeister, R. Wind and tidal mixing controls on stratification and dense water outflows in a large hypersaline bay. J. Geophys. Res. Oceans 2015, 120, 6034-6056. [CrossRef] 